\title{
Reflective Practice in Teacher Education: Perspectives and Methodological Considerations
}

\author{
Soumia Boumaza \\ Canterbury Christ Church University
}

\begin{abstract}
Since the introduction of reflective practice in education, it has been integrated as a core component in teacher education and training programmes, helping teachers gain a deeper understanding of their teaching practice and getting more control over the mechanisms of both the practicum and their teaching. Nevertheless, the literature underlying the concept shows some aspects of debate over its operationalisation in teacher education courses and the need for more evidence in relation to exploring the potential of reflection and what practitioners actually think of it. Based on such a need, this study investigates reflective practice in one of the preservice teacher training programmes, the CELTA course and explores teacher trainees' perceptions of the concept. In this sense, the study follows a qualitative research approach and uses insights from both ethnography and autoethnography. The ethnographic aspect manifests itself through the use of observations, interviews, and document analysis to better understand trainees' views of reflective practice and articulate a general grasp of the workings and nature of the concept in the CELTA course from a trainee perspective. The autoethnographic dimension, however, reveals itself through the importance of insider knowledge and its impact on understanding the setting and in getting to grips with trainees' understandings of reflective practice. The ethnographic aspect together with the autoethnography gives a detailed account of trainees' perspectives of reflection and their attitudes on its practice and implementation in the course. This paper thus gives an overview of the general findings related to trainees' understandings of reflection and outlines some methodological insights and considerations in relation to the research approach used in this study.
\end{abstract}

Key terms: CELTA course (Certificate of Teaching English to Speakers of Other Languages); teacher trainees; qualitative research; ethnography; auto ethnography. 